\title{
Producción in vitro de embriones bovinos: suplementación de los medios de cultivo con suero
}

\author{
In vitro production of bovine embryos: serum supplementation to the culture media \\ N Mucci ${ }^{1}$, J F Aller ${ }^{1}$, G G Kaiser ${ }^{1}$, F Hozbor ${ }^{1}$, R H Alberio ${ }^{1}$ \\ Instituto Nacional de Tecnología Agropecuaria, Estación Experimental Balcarce, Laboratorio de Biotecnología de la Reproduc- \\ ción, Balcarce, Argentina.
}

\begin{abstract}
SUMMARY
Techniques for producing bovine preimplantation embryos by in vitro maturation and fertilization, offers the potential for a large number of embryos at low cost to be used for basic scientific research (embryo development, transgenesis, cloning) or for commercial purposes. Embryo culture conditions can influence in vitro embryo development significantly, provoking deviations responsible for low quality compared with in vivo counterparts. In particular, serum supplementation alters both embryo morphology and quality and eliminating serum from the media could be beneficial to produce good quality embryos for cryopreservation and embryo transfer. The objectives of this review are to describe the general aspects of in vitro embryo culture and summerize some hypotheses about the way serum could alter embryo development and quality.
\end{abstract}

Palabras clave: producción in vitro, suero, calidad embrionaria.

Key words: in vitro production, serum, embryo quality.

\section{INTRODUCCION}

Durante muchos años se ha trabajado buscando reproducir artificialmente los eventos de la maduración y fertilización ovocitaria, y el desarrollo embrionario temprano. Así, lo que en principio sólo tenía fines de investigación, en los últimos años se ha comenzado a utilizar con propósitos comerciales.

Los resultados de producción in vitro de embriones en distintas especies fueron mejorando significativamente a medida que avanzaron los conocimientos acerca de sus requerimientos. Para ello, fue necesario transformar los medios de cultivo primitivos, muy complejos y suplementados frecuentemente con suero, en medios más definidos, en los cuales cada uno de sus componentes pudiera ser estudiado en función del efecto que genera sobre el desarrollo embrionario, su sobrevida poscriopreservación, la tasa de gestación y el porcentaje de crías viables.

SISTEMA DE PRODUCCION IN VITRO DE EMBRIONES. El proceso de producción in vitro de embriones bovinos puede dividirse en tres pasos fundamentales, los cuales,

Aceptado: 02.08.2005

1 Instituto Nacional de Tecnología Agropecuaria, Estación Experimental Balcarce, Laboratorio de Biotecnología de la Reproducción. Fax: 02266-439101. E-mail: nmucci@balcarce.inta.gov.ar Casilla de correo 276 (7620) Balcarce, Argentina independientemente del protocolo utilizado, en orden cronológico son: Maduración de ovocitos, Fecundación de ovocitos maduros, Cultivo de embriones.

Estos tres pasos, comprenden una compleja serie de procesos fisiológicos, muchos de los cuales son aún desconocidos, condicionando cada uno per se el éxito o el fracaso del siguiente. Luego de la maduración in vitro, aproximadamente el $90 \%$ de los ovocitos inmaduros puestos a cultivar, alcanzan la metafase II y expulsan el primer cuerpo polar entre las 16 y 24 hs de comenzada la maduración. De estos, aproximadamente el $80 \%$ es fecundado y comienzan a dividirse, al menos, hasta el estadio de 2 a 4 células. Sin embargo, sólo un 25-40\% alcanza el estadio de blastocisto (B) o blastocisto expandido (Bex) luego del cultivo durante 6-7 días. Esto indica que el cultivo embrionario, correspondiente al paso más prolongado dentro del proceso de producción in vitro, es el período en el que se establece el mayor porcentajes de pérdidas del sistema. A su vez, durante esta etapa, se define en gran medida la calidad de los embriones obtenidos (Enrigh y col 2000, Rizos y col 2002, Galli y col 2003, Lonergan y col 2003, Lonergan y col 2004).

\section{CULTIVO EMBRIONARIO}

Componentes de los medios de cultivo: parámetros biofísicos y elementos inorgánicos. Varios autores (Menezo y Khatchadourian 1991, Palasz 1996) coinciden en que los parámetros biofísicos y los elementos 
inorgánicos más importantes a controlar en los medios de cultivo embrionario son los siguientes:

- Osmolaridad. Teniendo en cuenta los valores observados en las secreciones uterinas, podría asumirse que lo óptimo sería $280 \pm 20 \mathrm{mOsm} / \mathrm{Kg}$. Sin embargo, existe evidencia que indica que valores de alrededor de $245 \mathrm{mOsm} / \mathrm{Kg}$ favorecerían el desarrollo embrionario (Duque y col 2003) ${ }^{\mathrm{b}}$.

- pH. La mayoría de los embriones de mamíferos cultivados in vitro desarrollan en $\mathrm{pH}$ neutro o ligeramente alcalino, encontrándose los mejores resultados entre 7,2 у 7,6 .

- $\mathrm{CO}_{2} \mathrm{y} \mathrm{O}_{2}$. La fase gaseosa más utilizada es aquella compuesta por $5 \% \mathrm{CO}_{2}$ en aire para la maduración ovocitaria y fertilización, y $5 \% \mathrm{O}_{2}, 90 \% \mathrm{~N}_{2}$ y $5 \% \mathrm{CO}_{2}$ para el desarrollo embrionario. Estas son similares a las registradas en el oviducto de algunas hembras mamíferas.

- El fluido oviductal bovino y ovino se caracteriza por bajos niveles de $\mathrm{Na}$ y altos niveles de K, comparados con los niveles plasmáticos. Estos dos elementos son cuidadosamente balanceados al formular los medios de cultivo, así como: magnesio, calcio, bicarbonato, sulfatos y fosfatos.

- El agua es el componente que participa en mayor proporción en la formulación de cualquier medio de cultivo y su grado de pureza está fuertemente relacionado con el desarrollo embrionario (MarquantLeguienne y Humblot 1998). Las fuentes de agua utilizadas han sido el agua de lluvia, la obtenida por sucesivas destilaciones (Boone y Shapiro 1990), o actualmente la producida por sistemas de purificación que utilizan el principio de ósmosis reversa. En estos últimos equipos, el grado de pureza del agua puede ser controlado mediante la determinación de su resistencia al paso de la corriente eléctrica (cuanto mayor sea esta, mayor será su pureza). La mayor resistencia ofrecida es 18,3 megaohms-cm a $25^{\circ} \mathrm{C}$.

Elementos orgánicos. Actualmente, existe una gran cantidad de información, no siempre coincidente, referida al efecto de ciertas hormonas, factores de crecimiento y compuestos macromoleculares, sobre el desarrollo embrionario. Sin embargo, dos componentes son constantes en las formulaciones finales de los medios de cultivo utilizados corrientemente en la producción in vitro de embriones. Estos son:

I. FUENTE DE ENERGIA. Las fuentes de energía más utilizadas en los medios de cultivo de embriones son, en general, el lactato, el piruvato y la glucosa (Palasz 1996).

Se ha demostrado que durante los primeros estadios, antes de la activación del genoma embrionario, los embriones utilizan preferentemente piruvato, lactato y glutamina como fuente de energía, aumentando considerablemente la utilización de glucosa en estadios más avan- zados de desarrollo (Reiger y col 1992, Gardner 1998, Krisher y Bavister 1998, Lane y Gardner 2000, Thompson, 2000).

La falta de utilización de la glucosa durante los primeros estadios estaría dada por la falta de actividad de la enzima fosfofructoquinasa (Gardner 1998). Esta enzima acelera la glucólisis catalizando la formación de fructosa 1-6 bifosfato a partir de fructosa 6 fosfato, y se encuentra controlada alostéricamente por el cociente ATP-ADP, particularmente alto en este período (Gardner 1998). En esta etapa, la adición de glucosa a los medios de cultivos no solamente no sería aprovechada, sino que, a su vez, generaría un efecto inhibitorio sobre el desarrollo embrionario (Takahashi y First 1992). Sin embargo, en embriones bovinos a partir del estadio de 8-16 células (Rieger y col 1992) y en respuesta a una alta demanda de energía necesaria para la compactación, y la formación y expansión del blastocele (Gardner 1998), el cociente ATP-ADP podría disminuir, y con ello, la inhibición ejercida sobre la enzima mencionada, con lo cual aumentaría el consumo de glucosa. Este metabolito también participa en la síntesis de precursores de ácidos nucleicos y de lípidos (Gardner y Lane 1998) y su disponibilidad sería importante durante la eclosión fuera de la zona pelúcida (Menezo y Khatchadourian 1991).

Con respecto a los lípidos, poco se sabe acerca de la importancia que tendrían en la producción de energía durante el desarrollo embrionario temprano (Thompson 2000). Sin embargo, en los últimos años se ha debatido la posibilidad de mejorar la viabilidad de los embriones criopreservados a través de la adición de ciertos componentes lipídicos a los medios de cultivo, específicamente ácido linoleico no como fuente energética, sino como fluidificador de las membranas plasmáticas (Imai y col 1997, Hochi y col 1999).

\section{FUENTE DE PROTEINA}

Aminoácidos. Varios autores (Gardner y Lane 1998, Lee y col 2004) indicaron que los aminoácidos se encuentran dentro de los elementos más importantes como participantes de la regulación del desarrollo embrionario. Estos elementos serían utilizados como fuente de energía, como buffer intracelular (Edwars y col 1998) y para la síntesis de proteínas, siendo incorporados por transportadores de membrana específicos regulados en función del estadio de desarrollo o en respuesta a señales externas (Van Winkle 2001).

Se ha demostrado que los aminoácidos no esenciales favorecerían el desarrollo en estadios tempranos, mientras que los esenciales harían lo mismo en embriones de más de ocho células (Gardner 1998, Thompson 2000, Van Winkle 2001). Este cambio en la utilización de aminoácidos, pareciera deberse a requerimientos específicos de las células embrionarias, en donde las células trofoblásticas, que dan origen a la placenta fetal, 
utilizarían aminoácidos no esenciales y glutamina, mientras que las de la masa celular interna, que originan al feto, tendrían preferencia por los esenciales (Gardner y Lane 1998).

Macromoléculas. Usualmente se agrega suero bovino y/o albúmina sérica bovina (BSA) como fuente de proteínas a los medios de cultivo embrionario (Wang y col 1997), aunque los resultados obtenidos tanto en producción como en sobrevida poscriopreservación tras su inclusión son contradictorios y motivo de numerosos estudios.

El suero constituye la fracción líquida resultante del proceso de coagulación sanguínea, tanto in vivo como in vitro, y su calidad, en términos de composición química, depende usualmente del tipo y estado del donante (suero fetal bovino (SFB), suero de ternero recién nacido, suero de novillo o vaca, suero de vaca en celo (SVC)), y de la partida o lote de formulación (Pinyopummintr y Bavister 1994) (cuadro 1).

La albúmina es una proteína plasmática de carácter ácido, soluble en agua, con un peso molecular aproximado de 69.000, y constituye uno de los componentes más importantes del suero sanguíneo. Debido a la presencia de grupos reactivos en su molécula, puede unirse a diferentes sustancias (ácidos grasos, hormonas, etc.) y transportarlas en sangre hasta sus órganos blanco. Junto con la inmunoglobulina $\mathrm{G}$, son las proteínas más abundantes del fluido oviductal (Leese 1988), y su pureza puede variar entre lotes (Kane y Headon 1980, Rorie y col 1994).

Algunos de los efectos benéficos que justifican la utilización del suero y la albúmina son:

- Proteger a los embriones en cultivo de sustancias tóxicas (ej. metales pesados).

- Aportar factores de crecimiento y ciertas hormonas.

- Reducir la tensión superficial del medio, evitando que los embriones se adhieran al instrumental (placas de cultivo, pipetas, tubos, etc.).
Tanto el suero como la BSA tienen un rol similar como suplemento proteico. Sin embargo, la posible presencia de elementos no identificados ligados a ambos determinan que algunos aspectos de su función no sean aún completamente comprendidos.

Efecto de la suplementación con suero sobre la cantidad y calidad de los embriones producidos in vitro. En los últimos años, el suero ha sido objeto de numerosos estudios, tendientes a definir si su adición es definitivamente necesaria para mejorar los resultados de producción in vitro, en función de la cantidad y calidad de los embriones obtenidos.

Se ha observado que la adición de suero a los medios de cultivo tiene un efecto bifásico sobre el desarrollo embrionario, inhibiendo los primeros estadios y estimulando el desarrollo de mórulas y blastocistos (Pinyopummintr y Bavister 1994, Thompson y col 1998). Al mismo tiempo, su empleo también se ha visto relacionado con una aceleración del desarrollo embrionario (Gómez y Diez 2000, Holm y col 2002), asociado a un número mayor de células embrionarias (Fouladi-Nashta y col 2005) y a una mejora en la tasa de producción y eclosión (Wang y col 1997, Gómez y Diez 2000). Sin embargo, otros autores observaron que, tanto la tasa de producción (Rorie y col 1994, Mucci y col 2003) como el número de células embrionarias (Thompson y col 1998, Gómez y Diez 2000, Sung y col 2004) no fueron afectados por la presencia o ausencia de suero. Contrariamente, Byrne y col (1999) y Ferguson y Leese (1999) encontraron una disminución en esta última variable cuando adicionaron suero en los medios de cultivo.

El suero es considerado un compuesto variable e indefinido (Gardner y Lane 1998), lo cual genera variaciones en la composición de los medios utilizados e interfiere con la repetibilidad de los resultados obtenidos. En este sentido se han observado diferencias en cuanto a la tasa de producción entre distintos ensayos publicados en los cuales se utilizó suero como suplemento proteico, y esto podría deberse a:

Cuadro 1. Análisis bioquímico del suero de novillo y fetal bovino de dos lotes distintos (CanSera International Inc. y Bocknek Lab). Adaptado de Palasz (1996) y Tornesi y Archer (1993).

Biochemical analysis of steer and fetal calf serum from two batches (CanSera International Inc. and Bocknek Lab). From Palasz (1996), and Tornesi and Archer (1993).

\begin{tabular}{|c|c|c|c|c|}
\hline \multirow[b]{3}{*}{ Determinación } & \multicolumn{4}{|c|}{ Valores Encontrados } \\
\hline & \multicolumn{2}{|c|}{ Suero de novillo } & \multicolumn{2}{|c|}{ Suero fetal bovino } \\
\hline & CanSera Int. & Bocknek Lab. & CanSera Int. & Bocknek Lab. \\
\hline Albúmina g/l & 36 & 34 & 19 & 19 \\
\hline Globulinas g/l & 36 & 37 & 19 & 19 \\
\hline Urea mM & 3,6 & 2,9 & 6,3 & 6,3 \\
\hline Glucosa mM & 1,3 & 0,8 & 7 & 7 \\
\hline Potasio mM & 6,3 & 5 & 3,44 & 13,6 \\
\hline Sodio mM & 140 & 140 & 135 & 135 \\
\hline Fósforo mM & 1,87 & 2,24 & 3,44 & 3,44 \\
\hline Calcio mM & 2,45 & 2,45 & 3,72 & 3,72 \\
\hline
\end{tabular}


- Utilización o no de cocultivo: Rorie y col (1994) observaron que el suero producía un efecto positivo sobre la tasa de producción de embriones sólo si el cultivo se efectuaba en cocultivo con células somáticas. Teniendo en cuenta el impacto positivo del suero sobre el cultivo de células somáticas (Gardner 1999), puede suponerse que el efecto benéfico de esta suplementación se ve potenciado a través de su acción sobre las células del cocultivo.

- Tipo de suero y momento de su inclusión: el suero más utilizado es el SFB. Si bien es difícil concluir acerca de cuáles son los constituyentes del suero que presentan actividad embriotrófica, las diferencias mostradas en el cuadro 1 entre dos tipos de suero, en términos de composición química, pueden determinar una fuente de variación capaz de tener un impacto significativo en la producción in vitro de embriones. Puede observarse que la concentración de glucosa es 6 veces superior en el suero fetal respecto al del bovino adulto. Teniendo en cuenta que la utilización de este elemento aumenta notablemente luego de los primeros 3-4 ciclos de división celular embrionaria (Rieger y col 1992, Lane y Gardner 2000, Thompson 2000), estas diferencias podrían contribuir a las variaciones observadas entre los ensayos. Con respecto a las proteínas, puede observarse también que sus concentraciones son superiores en un $85 \%$ en el caso del suero adulto respecto del fetal, y aunque poco se conoce acerca de la función de proteínas no específicas en el desarrollo embrionario, su metabolismo podría producir amoníaco, el cual, dependiendo de su concentración y del estadio embrionario que afecte, puede generar diferencias en cuanto a la producción total de embriones (Hammond y col 2000). En ambos tipos de suero, la relación proteína/glucosa es distinta y notablemente superior para el caso del bovino adulto, aunque no se dispone de información acerca de su posible impacto sobre el desarrollo embrionario.

- Variaciones en la concentración de factores embriotróficos: el factor transformante de crecimiento a (TGF, transforming growth factor) (Brison y Shultz 1997) y el factor de crecimiento similar a insulina 1 (IGF1, insulin-like growth factor) reducen la incidencia de apoptosis y aumentan el número de células embrionarias (Makarevich y Markkula 2002), mientras que el factor de necrosis tumoral a (TNF, tumor necrosis factor) induce apoptosis y fragmentación de ácidos nucleicos (Betts y King 2001). Según Byrne y col (1999), la utilización de suero en los medios de cultivo podría introducir cantidades variables de estos factores con efectos positivos y negativos sobre el desarrollo embrionario y esto podría depender de la partida, tipo de donante y del procedimiento de preparación, entre otros (Pinyopummintr y Bavister, 1994). Todos estos elementos podrían explicar la fal- ta de consistencia en los resultados de los distintos autores que utilizaron suero, por lo que Byrne y col (1999) concluyeron que el efecto embriotrófico del suero es complejo y que son necesarios más experimentos para clarificar los componentes específicos que lo producen.

Algunos efectos negativos que han sido atribuidos al uso de suero en los medios de cultivo son: alteraciones mitocondriales (Dorland y col 1994, Abe y col 1999b, Farin y col 2001), excesiva producción de lactato, presencia de células oscuras y granuladas en la masa celular interna (Bavister y col 1992, Krisher y col 1999), aumento de células apoptóticas (Byrne y col 1999), menor síntesis proteica (Kuran y col 2001) y disminución de la relación células de la masa celular interna: células trofoblásticas (Fouladi-Nashta y col 2005) y del número de complejos de unión entre las células embrionarias (Shamsuddin y Rodríguez-Martínez 1994). Además, se observaron alteraciones durante la preñez en hembras gestantes de embriones producidos con suero, tales como alargamiento del período de gestación (Thompson y col 1995) y nacimiento de crías con peso superior a lo normal (large offspring syndrome) (Farin y col, 2001).

Los embriones cultivados en presencia de suero presentan una morfología diferente comparados con los producidos sin suero (Shamsuddin y Rodríguez-Martínez, 1994, Gardner, 1999). Algunos autores observaron que, la suplementación con suero se encuentra asociada a un menor grado de compactación de las mórulas (Abe y col 1999b), y que tanto éstas como los blastocistos adquieren características similares a los obtenidos in vivo cuando son producidos en medios sin suero (Thompson 1997, Crosier y col 2001). Esto podría deberse a alteraciones a nivel de los complejos de unión intercelulares en respuesta a la suplementación con suero (Shamsuddin y Rodríguez-Martínez, 1994). Boni y col (1999) postularon que variaciones en la expresión de ARNm para la Connexina 43 (Cx43), una proteína que participa en la formación de las uniones de tipo gap en las células de los embriones en estadios de preimplantación, podría explicar algunas de las diferencias encontradas entre los embriones producidos in vitro y los obtenidos in vivo o, incluso, producidos en diferentes medios de cultivo incluyendo la presencia o ausencia de suero en los mismos. Cada estadio embrionario se caracteriza por la activación de conjuntos específicos de genes (Mohan y col 2002). Es así como, Lazzari y col (2002) y Rizos y col (2003) demostraron que los embriones producidos in vitro en cultivos suplementados con suero presentaron alteraciones en la expresión de genes que desempeñan un rol de particular importancia durante el desarrollo embrionario temprano. Una de estas fue precisamente la disminución de la transcripción del gen que codifica para Cx43, comparada con los embriones cultivados en un medio libre de suero. 
Efecto del suero sobre la viabilidad de los embriones criopreservados. 'Los embriones producidos in vitro presentan una alta sensibilidad a los procesos de criopreservación (Leibo y Loskutoff 1993, Pollard y Leibo 1994), siendo las diferencias morfológicas y/o metabólicas observadas respecto a los obtenidos in vivo las que parecerían ser las responsables (Massip y col, 1995). Leibo y Loskutoff (1993) determinaron que la densidad de los embriones producidos in vitro es menor que la de los obtenidos in vivo, y concluyeron que esto se debería a una mayor relación de lípidos: proteínas en el caso de los primeros.

La suplementación de los medios de cultivo con suero se ha relacionado con la acumulación anormal de gotas lipídicas intracitoplasmáticas (Shamsuddin y Rodríguez-Martínez 1994, Dorland y col 1994, Thompson y col 1995, Abe y col 1999ab). La presencia de estas estructuras en los embriones bovinos producidos in vitro se ha asociado a su alta sensibilidad a los procesos de criopreservación en general, y en los desarrollados en medios de cultivo suplementados con suero en particular (Abe y col 2002). Basados en los experimentos de Nagashima y col (1995) efectuados en embriones porcinos, distintos autores (Murakami y col 1998, Ushijima y col 1999, Diez y col 2001) reprodujeron la extracción de lípidos en embriones bovinos producidos in vitro mediante incubación con citocalasina (estabilizador del citoesqueleto por inhibición de la polimerización de filamentos de actina), centrifugación y remoción por microcirugía, observando un mayor porcentaje de sobrevida poscriopreservación en los embriones libres de gotas lipídicas.

Se ha demostrado que la acumulación de lípidos intracitoplasmáticos comienza a disminuir a partir del estadio de mórula, coincidiendo con la aparición de mitocondrias maduras (Abe y col 1999b), pudiendo cumplir, de este modo, la función de reserva para momentos de gran demanda energética, como lo es la formación del blastocele. Por el contrario, en presencia de suero, la acumulación lipídica aumenta a partir del mencionado estadio (Ferguson y Leese 1999). Estos resultados plantean un interrogante acerca de cuál es el rol de las gotas lipídicas en el citoplasma de las células embrionarias, ya que su eliminación no resulta en una disminución en la tasa de producción, sino que, además, mejora su calidad en términos de criorresistencia.

El origen de la acumulación de gotas lipídicas intracitoplasmáticas en los embriones producidos in vitro, cultivados en medios suplementados con suero, actualmente es desconocido, aunque existen dos teorías que podrían explicarlo:

- La presencia de suero genera un efecto deletéreo sobre la estructura mitocondrial, lo cual, al producir alteraciones morfológicas y funcionales en esta organela provocaría una acumulación anormal de gotas lipídicas producto de alteraciones en su metabolismo (Dorland y col 1994).

- Teniendo en cuenta la capacidad de captación de ácidos grasos, fosfolípidos y triglicéridos por parte de las células somáticas en cultivo, podría inferirse que la acumulación de lípidos intracitoplásmicos por parte de los blastómeros se debería a la incorporación de lipoproteínas presentes en el suero adicionado a los medios de cultivo (Thompson y col 1995, Abe y col 1999b).

Sata y col (1999) refuerzan la segunda hipótesis, al informar que el perfil de ácidos grasos contenidos en los embriones desarrollados en medios suplementados con suero fetal bovino es similar al que caracteriza al suero utilizado, diferenciándose, además, de los encontrados en los embriones producidos en medios de cultivo libres de suero. Estos autores concluyeron que la acumulación de ácidos grasos saturados de cadena larga e insaturados son de origen sérico.

Diversos autores (Yamashita y col 1999, Cho y col 2001, Abe y col 2002, Cho y col 2002) obtuvieron mejores tasas de sobrevida poscriopreservación en embriones producidos en medios suplementados con BSA y libres de suero, independientemente del sistema de criopreservación empleado. De acuerdo con Enright y col (2000), Massip (2001) y Lonergan y col (2003), la criopreservación representa un desafío para los embriones producidos in vitro, capaz de detectar diferencias de calidad embrionaria que no son evidenciadas mediante otras evaluaciones.

Si bien no está totalmente claro cuál es el rol endocelular por el que actuarían la albúmina y el suero, algunas de sus propiedades físicas podrían ser reemplazadas mediante la utilización de sustancias definidas. El uso de polímeros sintéticos, como el alcohol polivinílico y la polivinilpirrolidona, es frecuente desde hace varios años en la producción in vitro de embriones (Ectors y col 1992, Gardner y Lane 1998). Estos compuestos han demostrado proveer una buena actividad surfactante, similar a la albúmina, aunque se ha encontrado una menor tasa de producción de embriones y diferencias metabólicas importantes entre embriones cultivados con o sin estos componentes (Thompson 2000, Orsi y Leese 2004). Finalmente, se ha observado un menor porcentaje de gestación logrado con embriones producidos en medios suplementados con estos compuestos comparado con los obtenidos con embriones cultivados con suero (Jakobsen y col 1999). Otro compuesto utilizado con el fin de reemplazar la albúmina o el suero ha sido el hialuronato, con el cual se han informado resultados muy alentadores en cuanto a tasa de producción y sobrevida poscriopreservación (Gardner 1998, Stojkovic y col 2002).

Actualmente existen en el mercado compuestos formulados con el fin de remplazar el suero en los medios de cultivo de distintas líneas de células somáticas. Entre estos se encuentran el Ultroser $\mathrm{G}^{\circledR}$ (Invitrogen), un susti- 
tuto del SFB, y CPSR $-3^{\circledR}$ (Controlled Process Serum Replacement, SIGMA), el cual se obtiene por dializado del plasma bovino. Duque y col $\left(2003^{a}\right)$ demostraron que es posible producir embriones in vitro utilizando estos compuestos, y observaron que el reemplazo del suero por Ultroser ${ }^{\circledR}$ disminuyó significativamente la producción in vitro de embriones bovinos, mientras que utilizando CPSR $-3{ }^{\circledR}$ no obtuvieron diferencias en esta variable como tampoco en el número total de células embrionarias.

Finalmente, los conceptos presentados en esta revisión sugieren que el empleo de medios de cultivo libres de suero podría ser beneficioso para mejorar la calidad de los embriones producidos in vitro. Esto permitiría progresar en el entendimiento de los requerimientos embrionarios durante los estadios de preimplantación, ya que la eliminación de un compuesto altamente variable e indefinido, como lo es el suero, posibilitaría comprender la función que desempeña cada componente incluido en los medios de cultivo. Además, permitiría evitar las alteraciones embrionarias (morfológicas y fisiológicas) y durante la gestación, atribuidas a la utilización de suero en los medios de cultivo. Por último, una mejora en la calidad de los embriones producidos permitiría obtener mejores tasas de gestación, producidas principalmente por la transferencia de embriones criopreservados, posibilitando la aplicación comercial en gran escala de esta biotecnología.

\section{RESUMEN}

Las técnicas para producir embriones bovinos, en estadios de preimplantación mediante la maduración de ovocitos y su posterior fertilización in vitro, ofrece la posibilidad de obtener embriones a bajo costo para ser utilizados con fines de estudio (desarrollo embrionario temprano, transgénesis, clonación) o con propósitos comerciales. Las condiciones de cultivo in vitro pueden influenciar significativamente el desarrollo embrionario, determinando cambios responsables de su menor calidad, comparados con los embriones producidos in vivo. En particular, la adición de suero a los medios de cultivo altera tanto la morfología embrionaria como su calidad, y su eliminación posibilitaría producir embriones de buena calidad para ser criopreservados y transferidos. Los objetivos de esta revisión son describir los aspectos generales del cultivo in vitro de embriones y resumir algunas hipótesis referidas a los mecanismos por los cuales el suero podría alterar el desarrollo y la calidad embrionaria.

\section{BIBLIOGRAFIA}

Abe H, T Yamashita, T Itoh, T Satoh, H Hoshi. 1999a. Histochemical and ultraestructural evaluations of cytoplasmic lipid droplets in bovine embryos cultured in serum-free and serum-containing media. Theriogenology $51,232$.

Abe H, T Yamashita, T Itoh, T Satoh, H Hoshi. 1999b. Ultrastructure of bovine embryos developed from in vitromatured and -fertilized oocytes: comparative morphological evaluation of embryos cultured either in serum-free medium or in serum-supplemented medium. Mol Reprod Dev 53, 325-335.

Abe H., T Yamashita, T Satoh, H Hoshi. 2002. Acumulation of cytoplasmic lipid droplets in bovine embryos and cryotolerance of embryos developed in different culture systems using serum-free o serum-containing media. $\mathrm{Mol}$ Reprod Dev 61,57-66.

Bavister B, TA Rose-Hellekant, T Pinyopummintr. 1992. Development of in vitro matured/in vitro fertilized bovine embryos into morulae and blastocysts in defined culture media. Theriogenology 37,127-146.

Betts DH, WA King. 2001. Genetic regulation of embryos death and senescence. Theriogenology 55,171-191.

Boni R, E Tosti, S Roviello, B Dale. 1999. Intracellular communication in in vivo and in vitro produced bovine embryos. Biol Reprod 61,1050-1055.

Boone WR, SS Shapiro. 1990. Quality control in the in vitro fertilization laboratory. Theriogenology 33,23-50.

Brison DR, RM Shultz. 1997. Apoptosis during mouse blastocysts formation: evidence for a role for survival factors including TGF- $\alpha$. Biol Reprod 56,1088-1096.

Byrne AT, J Southgate, DR Brison, HJ Leese. 1999. Analysis of apoptosis in the preimplantation bovine embryos using TUNEL. J Reprod Fertil 117,97-105.

Cho SR, CG Hur, JG Lee, GL Rho, SY Choe, CS Park. 2001. Serum-free culture system enhances viability following cryopreservation of bovine embryos produced in vitro. Theriogenology 55,333.

Cho SR, SK Cho, SL Lee, HJ Lee, SY Choe, GJ Rho. 2002. Enhanced cryosurvival of bovine blastocysts produced in vitro in serum-free medium. J Assist Reprod Genet 19, 487-492.

Crosier AE, PW Farin, MJ Dykstra, JE Alexander, CE Farin. 2001. Ultrastructural morphometry of bovine blastocysts produced in vivo or in vitro. Biol Reprod 64,1375-1385.

Diez C, Y Heyman, D Le Bourhis, C Guyader-Joly, J Degrouard, JP Renard. 2001. Delipidating in vitro-produced bovine zygotes: effect on further development and consequences for freezability. Theriogenology 55,923-936.

Dorland M, DK Gardner, AO Trounson. 1994. Serum in synthetic oviduct fluid causes mitochondrial degeneration in ovine embryos. $J$ Reprod Fert 13,70.

Duque P, E Gómez, N Días, C Facal, C Hidalgo, C Diez. 2003a. Use of two replacements of serum during bovine embryo culture in vitro. Theriogenology 59,889-899.

Duque P, C Hidalgo, E Gómez, B Pintado, N Facal, C Diez. $2003^{b}$. Macromolecular source as dependent on osmotic pressure and water source: effects on bovine in vitro embryo development and quality. Reprod Nutr Dev 43,487-496.

Ectors FJ, RS Fontes, F Thonon, A Deval, JR Figueiredo, FJ Beckers, F Ectors. 1992. Effect of non-protein medium during in vitro maturation on in vitro development of bovine embryos. Theriogenology 37,206.

Edwards LJ, DA Williams, DK Gardner. 1998. Intracellular $\mathrm{pH}$ of the mouse preimplantation embryo: amino acid act as a buffers of intracellular pH. Hu. Reprod 13,3441-3448.

Enright BP, P Lonergan, A Dinnyes, T Fair, FA Ward, X Yang, MP Boland. 2000. Culture of in vitro produced bovine zygotes vs in vivo: implications for early embryo development and quality. Theriogenology 54,659-673. 
Farin PW, AE Crosier, CE Farin. 2001. Influence of in vitro system on embryo survival and fetal development in cattle. Theriogenology 55,151-170.

Ferguson EM, HJ Leese. 1999. Triglyceride content of bovine oocytes and early embryos. J. Reprod Fert 116,373-378.

Fouladi-Nashta AA, R Alberio, M Kafi, B Nicholas, KHS Campbell, R Webb. 2005. Differential staining combined with TUNEL labelling to detect apoptosis in preimplantation bovine embryos. Reproductive Biomedicine Online 10, 497-502.

Galli C, R Duchi, G Crotti, N Turini, N Ponderato, S Colleoni, I Lagutina, G Lazzari. 2003. Bovine embryo technologies. Theriogenology 59,599-616.

Gardner DK. 1998. Changes in the requeriments and utilization of nutrients during mammalian preimplantation embryo development and their significance in embryo culture. Theriogenology 49,83-102.

Gardner DK. 1999. Development of serum-free culture systems for the ruminant embryo and subsequent assessment of embryo viability. J Reprod Fert, Supp. 54,461-475.

Gardner DK, M Lane. 1998. Culture of viable human balstocysts in defined sequential serum-free media. Hum Reprod 13,148-159.

Gómez E, D Diez. 2000. Effects of glucose and protein sources on bovine embryo development in vitro. Anim Reprod Sci 58,23-37.

Hammond DS, S Wang, GR Holyoak. 2000. Effects of ammonia during different stages of culture on development of in vitro produced bovine embryos. Anim Reprod Sci 59,23-30.

Hochi S, K Kimura, A Hanada. 1999. Effect of linoleic acidalbumin in the culture medium on freezing sensitivity of in vitro-produced bovine morulae. Theriogenology 52, 497-504.

Holm P, PJ Booth, H Callensen. 2002. Kinetics of early in vitro development of bovine in vivo- and in vitro-derived zygotes produced and/or cultured in chemically defined or serumcontaining media. Reproduction 123,553-565.

Imai K, S Kobayashi, Y Goto, O Dochi, I Shimoshira. 1997. Cryopreservation of bovine embryos obtained by in vitro culture of IVM-IVF oocytes in the presence of linoleic acid albumin. Theriogenology 47,347.

Jacobsen H, M Schmidt, P Holm, PT Sangild, G Vajta, T Greve, H Callensen. 1999. Body dimensions and birth and organ weights of calves derived from in vitro produced embryos cultured with or without serum and oviduct epithelium cells. Theriogenology 53,1761-1769.

Kane MT, DR Headon. 1980. The role of commercial bovine serum albumin preparation in the culture of one-cell rabbit embryos to blastocysts. J Reprod Fert 60,469-475.

Krisher RL, BD Bavister. 1998. Responses of oocytes and embryos to the culture environment. Theriogenology 49,103-114.

Krisher RL, M Lane, BD Bavister. 1999. Developmental competence and metabolism of bovine embryos cultured in semi-defined and defined culture media. Biol Reprod 60,1345-1352.

Kuran M, JJ Robinson, ME Staines, TG McEvoy. 2001. Development and de novo protein synthetic activity of bovine embryos produced in vitro in different culture systems. Theriogenology 55, 593-606
Lane M, DK Gardner. 2000. Lactate regulates pyruvate uptake and metabolism in the preimplantation mouse embryo. Biol Reprod 62,16-22.

Lazzari G, C Wrenzycki, D Herrmann, R Duchi, T Kruip, H Niemann, C Galli. 2002. Cellular and molecular deviations in bovine in vitro-produced embryos are related to the large offspring syndrome. Biol Reprod 67,767-775.

Lee ES, Y Fukui, BC Lee, JM Lim, WS Hwang. 2004. Promoting effect of amino acids added to a chemically defined medium on blastocyst formation and blastomere proliferation of bovine embryos cultured in vitro. Anim Reprod Sci 84,257-267.

Leese HJ. 1988. The formation and function of oviduct fluid. J Reprod Fertil 82,843-856.

Leibo P, NM Loskutoff. 1993. Cryobiology of in vitro-derived bovine embryos. Theriogenology 39,81-94.

Lonergan P, D Rizos, J Kanka, L Nemcova, AM Mbaye, M Kingston, M Wade, P Duffy, MP Boland. 2003. Temporal sensitivity of bovine embryos to culture environment after fertilization and the implications for blastocyst quality. Reproduction 126,337-346.

Lonergan P, HG Pedersen, D Rizos, T Greve, PD Thomsen, T Fair, A Evans, MP Boland. 2004. Effect of the postfertilization culture environment on the incidence of chromosome aberrations in bovine blastocysts. Biol Reprod 71,1096-1100.

Makarevich AV, M Markkula. 2002. Apoptosis and cell proliferation potential of bovine embryos stimulated with insulin-like growth factor 1 during in vitro maturation and culture. Biol Reprod 66:386-392.

Marquant-Leguienne B, P Humblot. 1998. Practical measures to improve in vitro blastocysts production in the bovine. Theriogenology 49,3-11.

Massip A, 2001. Cryopreservation of embryos of farm animals. Reprod Dom Anim 36,49-55.

Massip A, P Mermillod, A Dinnyés. 1995. Morphology and biochemistry of in vitro produced bovine embryos: implication for their cryopreservation. Hum Reprod 10,3004-3011.

Menezo YJR, CJ Khatchadourian. 1991. The laboratory culture media. Assist Reprod Rev 6,136-143.

Mohan M, S Ryder, PL Claypool, RD Geisert, JR Malayer. 2002. Analysis of gene expression in the bovine blastocyst produced in vitro using suppression-subtractive hybridization. Biol Reprod 67,447-53.

Mucci N, JF Aller, F Hozbor, RH Alberio. 2003. Efecto del suero sobre la producción in vitro de embriones bovinos. Rev Arg Prod Anim 23,274-275.

Murakami M, T Otoi, C Sumantri, T Suzuki, 1998. Effect of centrifugation and lipid removal on the cryopreservation of in vitro produced bovine embryos at the eight-cell stage. Cryobiology 36,206-212.

Nagashima H, N Kashiwazaki, RJ Ashman, CG Grupen, MB Nottle. 1995. Cryopreservation of porcine embryos. Nature 374,416 .

Orsi NM, HJ Leese, 2004. Amino acid metabolism of preimplantation bovine embryos cultured with bovine serum albumin or polyvinyl alcohol. Theriogenology 61,561-572.

Palasz AT. 1996. Cultivo de embriones bovinos: recientes avances en el desarrollo de sistemas de cultivos defini- 
dos. En: II ${ }^{o}$ Simposio Internacional de Reproducción Animal. Instituto de Reproducción Animal Córdoba. Argentina. Pp 185-94.

Pinyopummintr T, BD Bavister. 1994. Development of bovine embryos in a cell-free medium: effects of type of serum, timing of its inclusion and heat inactivation. Theriogenology 41,1241-1249.

Pollard JW, P Leibo. 1994. Chilling sensitivity of mammalian embryos. Theriogenology 41,107-112.

Rieger D, NM Loskutoff, KJ Betteridge. 1992. Developmentally related changes in the metabolism of glucose and glutamine by cattle embryos produced and co-cultured in vitro. Theriogenology 95,585-595.

Rizos D, F Ward, P Duffy, MP Boland, P Lonergan. 2002. Consequences of bovine oocyte maturation, fertilization or early embryo development in vitro versus in vivo: implications for blastocysts quality. Mol Reprod Dev 61,234-248.

Rizos D, A Gutiérrez-Adán, S Pérez-Garnelo, J De La Fuente, MP Boland, P Lonergan. 2003. Bovine embryo culture in the presence or absence of serum: implication for blastocysts development, cryotolerance, and messenger RNA expression. Biol Reprod 68,236-243.

Rorie RW, TD Lester, GF Miller, DW Gliedt, RW McNew. 1994. Effects of protein source and co-culture on bovine embryo development in synthetic oviductal fluid medium. Theriogenology 42,385-395.

Sata R, H Tsuji, H Abe, S Yamashita, H Hoshi. 1999. Fatty acid composition of bovine embryos cultured in serumfree and serum-containing medium during early embryonic develpment. J Reprod Dev 45,97-103.

Shansuddin M, H Rodríguez-Martínez. 1994. Fine structure of bovine blastocysts developed either in serum-free medium or in convencional co-culture with oviduct epithelial cells. $J$ Vet Med 41,307-316.

Stojkovic M, S Kölle, S Peinl, P Stojkovic, V Zakhartchenko, JG Thompson, H Wenigerkind, HD Reichenbach, F Sinowatz, E Wolf. 2002. Effects of high concentration of hyaluronan in culture medium on development and survival rates of fresh and frozen-thawed bovine embryos produced in vitro. Reproduction 124,141-153.
Sung LY, F Du, J Xu, W Chang, TL Nedambale, J Zhang, S Jiang, XC Tian, X Yang. 2004. The differential requirement of albumin and sodium citrate on the development of in vitro produced bovine embryos. Reprod Nut Dev 44, 551-564.

Takahashi Y, NL First. 1992. In vitro development of bovine one-cell embryos: influence of glucose, lactate, pyruvate, amino acids and vitamins. Theriogenology 37,963-978.

Thompson JG. 1997. Comparison between in vivo-derived and in vitro-produced pre-elongation embryos from domestic ruminants. Reprod Fertil Dev 9,341-354.

Thompson JG. 2000. In vitro culture and embryo metabolism of cattle and sheep embryos - a decade of achievement. Anim Reprod Sci 60-61,263-275.

Thompson JG, DK Gardner, PA Pugh, WH McMillan, ER Tervit. 1995. Lamb birth weigth is affected by culture system utilized during in vitro pre-elongation development of ovine embryos. Biol Reprod 53,1385-1391.

Thompson JG, NW Allen, LT McGowan, ACS Bell, MG Lambert, HR Tervit. 1998. Effect of delayed supplementation of fetal calf serum to culture medium on bovine embryo development in vitro and following transfer. Theriogenology 49,1239-1249.

Tornesi B, J Archer. 1993. Importancia de los componentes de los medios de cultivo en la viabilidad embrionaria. En: I Simposio Internacional de Reproducción Animal. Instituto de Reproducción Animal. Córdoba. Argentina.

Ushijima H, H Yamakawa, H Nagashima. 1999. Cryopreservation of bovine pre-morula-stage in vitro matured/in vitro fetrilized embryos after delipidation and before use in nucleus transfer. Biol Reprod 60,534-539.

Van Winkle LJ. 2001. Amino acid transport regulation and early embryo development. Bio Reprod 64,1-12.

Wang S, Y Liu, GR Holyoak, TD Bunch. 1997. The effects of bovine serum albumin and fetal bovine serum on the development of pre- and postcleveage-stage bovine embryos cultured in modified CR2 and M199 media. Anim Reprod Sci 48,37-45.

Yamashita S, H Abe, T Itoh, T Satoh, H Hoshi. 1999. A serumfree culture system for efficient in vitro production of bovine blastocysts with improved viability after freezing and thawing. Cytotechnology 31,123-131. 